\title{
AKTUALISASI NILAI-NILAI KEMANDIRIAN DALAM MEMBENTUK KARAKTER MANDIRI SISWA
}

\author{
Yusutria $^{1}$, Rina Febriana ${ }^{2}$ \\ 1,2 Sekolah Tinggi Keguruan dan Ilmu Pendidikan PGRI SUMATERA BARAT \\ Jln. Gn. Pangilun, Padang Utara Kota Padang, Sumatera Barat 25173 \\ Email:1yusutriayusut@ymail.com, 2rinafebriana0502@gmail.com
}

DOI: $10.29313 /$ tjpi.v8i1.4575

Accepted: May 10th, 2019. Approved: October 10th, 2019. Published: October 14th, 2019

\begin{abstract}
Islamic boarding schools teach students their self-reliance values, which can shape their personalities in being independent so that they are in accordance with one of the goals of Indonesian education, which is to become independent human beings. For this reason, it is necessary to study the actualiaation in shaping the character of the independence of their students. This research is field research using a descriptive qualitative approach. The source of data comes from the primary and secondary as well as collecting data through observation, interviews, and documentation. The results of his research can be seen from the factors of awareness, regulation, and habits of being a supporter in shaping independent character, while age and psychology become obstacles in shaping independence in students. The ability to manage finances, time, social life is a reflection of the impact of positive values in the actualization of independence in the independent character of students.
\end{abstract}

Keywords: Actualization; Independence; Character.

\begin{abstract}
Abstrak
Pondok pesantren mengajarkan kepada siswanya nilai-nilai kemandirian, yang dapat membentuk kepribadiannya dalam bersikap mandiri, sehinga sesuai dengan salab satu tujuan pendidikan Indonesia yaitu menjadi insan mandiri. Untuk itu dibutubkan perlu dikaji tentang aktualisasinya dalam membentuk karakter kemandirian siswanya. Penelitian ini adalah penelitian lapangan dengan menggunakan pendekatan kualitatif deskriptif. Adapun sumber data bersumber dari primer dan skunder serta pengumpulan data melalui observasi, wawancara, dan dokumentasi. Hasil penelitiannya dapat dilihat dari faktor kesadaran, suritauladan dan kebiasaan menjadi pendukung dalam membentuk karakter mandiri, sementara usia dan spikologi menjadi penghambat dalam membentuk kemandirian dalam diri siswa. Adanya kemampuan dalam mengelola keuangan, waktu, hidup sosial merupakan cerminan akan adanya dampak nilai positif dalam aktualisasi kemandirian dalam karakter mandiri siswa.
\end{abstract}

Kata Kunci: Aktualisasi; Kemandirian; Karakter. 


\section{PENDAHULUAN}

Pendidikan nasional berfungsi untuk mengembangkan kemampuan dan membentuk manusia yang berkarakter dalam rangka mencerdaskan kehidupan bangsa. (Sisdiknas. UU. No. 20 tahun 2003). Untuk membentuk manusia Indonesia seutuhnya dan memiliki karakter yang baik dapat melalui nilai-nilai kemandirian yang ada dalam diri siswa. Nilai-nilai kemandirian tersebut akan terbangun dan teralisasi jika didukung oleh berbagai elemen, baik keluarga, pemerintah, masyarakat dan lembaga/sekolah, karena lembaga pendidikan memiliki peran dalam pembentukan kepribadian dan karakter serta peradaban manusia yang beradab. (Deni Damayanti. 2014: 5), (Yusutria. 2018: 84). Seseorang dapat membentuk dan membuat suatu keputusan, sikap, perkataan dan perbuatan sehingga akan membentuk jiwa karakter. (Hidayatullah. 2009: 9), (Novi Irma Lutviyanti. 2013: 2).

Adapun lembaga pendidikan tersebut diantaranya adalah pondok pesantren, karena pondok pesantren termasuk lembaga yang melakukan pembinaan moral dan dakwah. (Mujamil Qomar. 2005: xxiii). Lembaga pendidikan pesantren sebagai lembaga pendidikan asli Indonesia yang dikenal dengan indigenous, karena mengakar sehingga mampu bertahan sampai saat sekarang ini, walaupun banyak terdapat perubahan dan perkembangan yang memiliki pengaruh besar dalam kehiduapn Indonesia. (Madjid. 1997: 3), (Haedari. 2004: 102-103), (M.Sulthon Masyhud. 2004: 8). Pesantren merupakan tempat untuk melestarikan dan melanjutkan sistem pendidikan rakyat dan mampu mengubah sistem pendidikan aristokratis menjadi demokratis. (Asep Kurniawan. 2015: 6). Sehingga lembaga pendidikan pesantren diminta untuk mencarikan solusi dalam mengantarkan masyarakat dalam mengatasi kemandirian, yang sesuai dengan tujuan pendidikan nasional. (Abd A’la. 2006: 8-9).
Memberikan pemahaman kepada siswa (koqnitif), sehingga terasa bagi siswa tersebut akan suatu perbuatan dan tindakan yang salah atau benar (afektif), yang menjadikan siswa tersebut terbiasa dalam melakukan perbutan tersebut (psikomotorik). (Syarbini. 2012: 16-17). Siswa yang sanggup untuk beridri sendiri dan memiliki rasa tanggung jawab terhadap segala tindakan dan tingkahlaku perbuatan yang dilakukannya demi memenuhi akan keperluannya sendiri, maka inilah yang disebut dengan kemandirian. (Kartini Kartono. 1990: 10). Melihat akan tujuan pendidikan nasional Indonesia yang meminta kepada hasil didikan di lembaga pendidikan agar peserta didik tersebut mandiri dalam menentukan masa depannya sehingga menjadi manusia yang seutuhnya. Dengan adanya nilai-nilai kemandirian yang ada di lembaga pendidikan pondok pesantren, sehingga perlu dikaji lebih lanjut bagaimana aktualisasi nilai-nilai kemandirian yang diajarkan dilembaga tersebut dapat membentuk karakter kemandirian siswanya?.

\section{METODOLOGI PENELITIAN}

Jenis penelitian ini penelitian lapangan. Metode penelitian yang digunakan adalah metode deskriptif dengan pendekatan kualitatif dengan tujuan memaparkan secara realita di lapangan, berdasarkan tertulis, lisan dan prilaku yang diamanati. (Sugiyono. 2013: 3), (Kasiram. 2010: 172). Sumber data penelitian yang digunakan berasal dari sumber data primer dan skunder. (Etta Mamang Sangadji. 2010: 171), (Lexy Moleong. 2002: 112). Metode pengumpulan data berdasarkan pada observasi, wawancara, dan dokumentasi. (Riduwan. 2005: 30), (Arikunto. 2002: 188).

\section{TINJAUAN PUSTAKA}

\section{Kemandirian}

Kemandirian berasal dari kata kemandiri-an, yang merupakan berdiri sendiri tanpa adanya ketergantungan pada pihak 
lain. (Depdiknas. 1990: 625). Kemandirian merupakan suatu kekuatan yang ada dalam diri seseorang yang diperoleh melalui proses kedirian dan individuasi, yang bertanggungjawab atas segala perbuatan dan tindakan yang dilakukannya. (Parker. 2005: 226). Kemandirian secara emosional yang dapat mengontrol emosi, baik dalam kemandirian dalam mengatur ekonomi dan secara intelektual serta kemandirian dalam sosial. (Sri Arfiah. 2017: 77). Sikap kemandirian yang ada dalam diri siswa akan berdampak terhadap perubahan sikap, perilaku, dan kepribadian yang sesuai dengan tuntutan dan kebutuhan yang didasari agama. (Yusutria. 2013: 158).

Sehingga kemandirian merupakan sikap, perbuatan dan prilaku yang akan membawa percaya diri akan kemampuannya dalam menghadapi suatu permasalahan dan tidak memiliki ketergantungan pada pihak lain.

\section{Karakter}

Karakter merupakan suatu kepribadian khusus yang dimiliki oleh seseorang dalam membentuk mental, moral dan akhlaq yang berbudi pekerti yang baik dan penuh rasa tanggung jawab. (Hidaytullah. 2010: 14), (Wibowo. 2012: 73). Pembentukan karakter mandiri dalam jiwa siswa pada hakekatnya dapat dikembangkan melalui kedisiplinan yang mantap, adanya semangat dalam melaksanakan secara rutinitas dan bersungguh-sungguh, didasari dengan nilai agama yang matang dengan mengedepankan jiwa kebersamaan yang penuh dengan kasih sayang, kesederhanaan, jujur dan jiwa keikhlasan. (Mangun Budiyanto dan Imam Machali. 2014: 108).

Adanya semangat yang disertai penuh dengan kedisiplinan diri dalam mengerjakan sesuatu dengan rasa tanggungjawab akan kasih sayang dan kesadaran yang ada dalam diri seseorang sehingga orang tersebut dinyatakan memiliki karakter atau kepribadian yang baik.

\section{HASIL DAN PEMBAHASAN PENELITIAN}

\section{Faktor Pendukung}

Kesadaran dalam berprilaku mandiri yang berdasarkan hati nurani. Hal tersebut dengan hasil wawancara yang telah dilakukan dengan guru yang memngajar di pesantren tersebut, sebagaimana dipaparkan:

"dalam mendukung semangat akan kemandirian dan menanamkan jiwa yang mandiri kepada seluruh siswa, dibutuhkan kesadaran yang mendalam dalam dirinya, sebab siswa tahu, bahwa dengan jiwa mandiri yang dimilikinya, siswa tersebut akan mampu membawa dirinya ke arah yang lebih baik dalam berbuat dan berprilaku disertai dnegan rasa tanggung jawab dalam setiap perbuatan dan tindakan yang di ambilnya."

Hal tersebut tercermin dalam kegiatan yang dilakukan oleh siswa dalam berbagai macam bentuk kegiatan baik dalam berorganisasi, kegiatan rutinitas seperti makan, belajar, mencuci, mandi, sholat dan olah raga serta mengatur keuangan. Hal tersebut sesuai dengan paparan yang dipaparkan oleh (M. Japar. 2018: 88), bahwa kemandirian akan terbentuk dengan memiliki rasa tanggung jawab yang penuh dengan kepercayaan dalam diri serta keteguhan pendirian dan berani bertanggung jawab.

\section{Keteladanan}

Hal tersebuta berdasarkan dengana hasil wawancara dengan nara sumber, bahwa:

"Adanya ketauladanan dari pihak pimpinan pesantren dan dari guru untuk berbuat mandiri dalam setiap tindakan, perkataan maupun perbuatannya yang disertai dengan rasa tanggungjawab yang besar dari setiap permasalahan yang ditimbulkan."

Kemandirian akan terealisasi dalam diri seseorang akan terbentuk dari contoh yang diberikan oleh gurunya dalam ritual ibadah, kehidupan sehari-hari. Hal tersebut sesuai dengan Zuhdy Mukhdar (1989: 19). 
Terbentuknya jiwa kemandirian dalam diri siswa bisa berasal dari suritauladan yang diberikan oelh pimpinan pondok dan para ustadznya.

\section{Pembiasaan}

Adanya kebiasaan dalam menjadikan watak mandiri dalam diri seorang siswa baik dalam setiap pekerjaannya yang dilakukanya dan pendidikan yang didapatkannya akan menjadikan siswa tersebut mandiri dalam setiap yang dilakukakannya. (hasil wawancara).

Hal tersebut sesuai dengan Abuddin Nata ( 2010: 157), bahwa pembentukan karakter dalam kemandirian tersebut bisa terbentuk melalui pendidikan agama, pembudayaan, dan pembiasaan. Pembentukan sikap kemandirian tersebut tercermin dalam panca jiwa yang ada dalam pesantren yaitu keikhlasan, kesederhanaan, kemandirian, ukhuwwah islamiyah dan kebebasan. (Yusutria. 2014: 153), (Abdullah Syukri Zarkasyi. 1998: 221-224).

\section{Faktor Penghambat}

Faktor usia. Faktor menjadi faktor penghambat dalam membentuk kepribadian yang mandiri, hal tersebut dapat dipahami dari hasil wawancara:

"dalam pembentukan karakter yang mandiri dalam diri seorang siswa mengalami penghambatan dan kendala, diantaranya faktor usia, karena siswa yang mengenyam pendidikan di pesantren ini, kebanyakan tamatan sekolah dasara (SD), sehingga jiwa dan mentalnya belum stabil dan masih tergolong dalam masa puberitas"

Faktor psikologis sebagai penghambat dalam pembentukan karakter mandiri dalam diri siswa. Hal tersebut dapat dipahami dari hasil wawancara:

"Siswa yang melanjutkan studinya/pendidikannya banyak dari tingkatan dasar/sekolah dasar (SD), sehingga jiwa dan mentalnya masih anak-anak dan masih banyak memerlukan rasa perhatian yang mendalam dari kedua orang tuanya, sehingga mental untuk mandiri tersebut belum tertatam dalam dirinya."

\section{Aktualisasi Kemandirian}

Aktualisasi kemandirian dalam membentuk kepribadian diri siswa dapat dilihat dari setiap tindakan dan prilaku yang dilakukannya dalam keseharian. Sebagaimana hasil observasi yang penulis lakukan, bahwa:

"Siswa disiplin dalam setiap melakukan kegiatan yang ada di lingkungan pesantren, dengan adanya kesiplinan dalam dirinya menjadikan siswa tersebut mandiri dalam mengatur waktu. Dalam segi ekonomi, siswa mampu mengatur keuangannya dan mengelola uang yang di dapatkan dari orang tuanya, sehingga siswa tersebut tidak boros. Adanya sikap ketidak borosan dalam mengelola keuangan menjadikan siswa tersebut mampu mandiri dalam mengelola keuangannya."

Kemamdiriannya yang dalam diri siswa, secara tidak langsung tercermin dalam setiap tindakan dan perbuatan yang dilakukannya, baik dalam kegiatan harian, mingguan, bulanan dan tahunnan, yang disertai dengan semangat penuh dengan kejujuran dan rasa tanggung jawab yang mendalam.

\section{KESIMPULAN}

Terbentuknya karakter yang mandiri dalam diri siswa didasari akan kedasaran yang mendalam dalam dirinya untuk menjadi manusia yang penuh rasa tanggungjawab ditunjang dari kebiasaan yang tertanam dalam diri, karena adanya suritauladan yang dicontohnya dari pimpinan, guru dan teman sebanya. Faktor usia dan psikologi menjadi penghambat dalam membentuk kemandirian siswa, karena usianya masih dalam masa puberitas yang masih banyak membutuhkan rasa kasih sayang dan perhatian dari.orang tuanya.

Adanya semangat dalam menentukan tujuan akan keberhasilan dalam dirinya membawa dampak perubahan yang 
positif, baik tercermin pada perkataan, perbuatan dan tindakanya yang disertai dengan rasa penuh tanggungjawab.

\section{DAFTAR PUSTAKA}

A'la, Abd. (2006). Pembaharuan Pesantren. Yoqyakarta: Pustaka Pesantren.

Arfiah, Sri. (2017). Penguatan Karakter Kemandirian dan Tanggung Jawab Melalui Perkuliahan Kepramukaan Dalam Upaya Mempersiapkan Mahasiswa PPKN Sebagai Pembina Ekstrakurikuler di Sekolah. Jurnal Pendidikan Ilmu Sosial. Vol. 27, No. 2.

Arikunto, Suharsimi. (2002). Prosedur Penelitian Suatu Pendekatan Praktek. Jakarta: Rineka Cipta.

Budiyanto, Mangun \& Machali, Imam. (2014). Pembentukan Karakter Mandiri Melalui Pendidikan Agriculture di Pondok Pesantren Islamic Studies Center Aswaja Lintang Songo Piyungan Bantul Yoquakarta. Jurnal Pendidikan karakter, Tahun IV, Nomor 2.

Damayanti, Deni. (2014). Panduan Implementasi Pendidikan Karakter di Sekolah. Yoqyakarta: Araska.

Depdiknas. (1990). Kamus Besar Bahasa Indonesia. Jakarta: Balai Pustaka.

Haedari, Amin. (2004). Masa Depan Pesantren Dalam Tantangan Modernitas dan Tantangan Kompleksitas Global. Jakarta: IRD Press.

Hidaytullah, Muhammad Furqon. (2009). Guru Sejati: Membangun Insan Berkarakter Kuat dan Cerdas. Surakarta: Yuma Pustaka.

Hidayatullah, Furqon. (2010). Pendidikan Karakter: Membangun Peradaban Bangsa. Surakarta: Yuma Pustaka.

Japar, M. (2018). Pembentukan Karakter Kemandirian Melalui Kegiatan OSIS di Sekolah Menengah Atas. JPIS. Jurnal Pendidikan dan Ilmu Sosial. Vol. 28, No. 1.

Kartono, Kartini. (1990). Psikologi Anak. Bandung: Mandar Maju.
Kasiram. (2010). Metodologi Penelitian Kualitatif-Kuantitatif. Malang: UIN Maliki Press.

Kurniawan, Asep. (2015). Pendidikan Karakter di Pondok Pesantren Dalam Menjawab Krisis Sosial. Edueksos: Jurnal Pendidikan Sosial \& Ekonomi. Vol. 4, No. 2.

Madjid, Nurcholish. (1997). Bilik-Bilik Pesantren Sebuab Potrek Perjalanan. Jakarta: Paramadina.

Masyhud, M. Sulthon \& Khusnurdilo. (2004). Manajemen Pondok Pesantren. Jakarta: Diva Pustaka.

Moleong, Lexy. (2002). Metode Penelitian Kualitatif, Bandung: Remaja Rosdakarya.

Mukhdar, Zuhdy. (1989). KH. Ali Ma'shum Perjuangan dan Pemikirannya. Yoqyakarta: Tnp.

Nata, Abuddin. (2010). Akblak Tasawnf. Jakarta:Rajawali Press.

NI, Lutviyanti. (2013). Internalisasi Pendidikan Karakter Dalam Membentuk Kemandirian Anak di Pondok Asib Sesami Kecamatan Baturetno Kabupaten Wonogiri. Jurnal FKIP. Vol. 3, Nomor 2.

Parker, Deborah. (2005). Menumbubkan Kemandirian dan Harga Diri Anak. Jakarta: Prestasi Pustakaray.

Qomar, Mujamil. (2005). Pesantren dari Transformasi Metodologi Menuju Demokratisasi. Jakarta: Erlangga.

Riduwan. (2005). Skala Pengukuran V ariabelvariabel Penelitian. Bandung: Alfabeta.

Sangadji, Etta Mamang. (2010). Metodologi Penelitian: Pendekatan Praktis Dalam Penelitian, Yoqyakarta: CV. Andi Offset.

Sugiyono. (2013). Metodologi Penelitian Kombinasi (Mixed Methods), Jakarta: Alfabeta.

Syarbini, Amirullah. (2012). Buku Pintar Pendidikan karakter: Panduan Lengkap Mendidik Karakter Anak di Sekolah, Madrasah,dan Rumah. Jakarta: as@Prima. 
Yusutria, Rina Febriana / Ta'dib: Jurnal Pendidikan Islam, Vol. 8 No. 1 (2019) 577-582 ISSN 1411-8173 | E-ISSN 2528-5092

https://ejournal.unisba.ac.id/index.php/tadib/article/view/4575

Undang-undang SISDIKNAS RI, Nomor 20 Tahun 2003.

Wibowo, Agus. (2012). Pendidikan Karakter Usia Dini (Strategi Membangun Karakter Usia Dini). Yoqyakarta: Pustaka Belajar.

Yusutria. (2013). Persepsi Santri Terbadap Kemandirian Dalam Pendidikan Islam di Pondok Pesantren Thawalib Padang. Jurnal Menara Ilmu. Vol. IX. No. 42. Yusutria. (2014). KH. Imam Zarkasyi Dalam Pembaharuan Pendidikan Pesantren.
Jurnal Menara Ilmu. Vol. VIII. No. 42.

Yusutria. (2018). Analisis Mutu Lembaga Pendidikan Berdasarkan Fungsi Manajemen di Pondok Pesantren Thawalib Padang Sumatera Barat. Ta'dib: Jurnal Pendidikan Islam, Vol VII, No. 2.

Zarkasyi, Abdullah Syukri. (1998). Langkah Pengembangan Pesantren. Yoqyakarta: Pustaka Pelajar. 